\title{
Research on Key Issues and Countermeasures of Internationalization of Chinese Enterprise Standards
}

\author{
Wei PAN ${ }^{\mathrm{a}, 1}$, Lifei YANG ${ }^{\mathrm{b}}$, and Lixin YIN $^{\mathrm{a}}$ \\ ${ }^{a}$ China National Institute of Standardization \\ ${ }^{b}$ State Grain and Reserves Bureau Standard Quality Center, China
}

\begin{abstract}
This paper mainly discusses the current situation of the internationalization development, the issues and challenges faced of enterprise standards in China in recent years, and the countermeasures and suggestions to be taken in the future. The research methods of qualitative analysis and case studies are mainly adopted. Both primary and secondary information resources are collected for an analysis and recognition of the progress of internationalization of Chinese enterprise standards. The key issues in the internationalization process of Chinese enterprise standards are put forward through analysis of the lessons learned such as lack of consistency in technology standards and real needs in the process of internationalization of Chinese enterprise standards in the last two decades, especially in the practice of participating in foreign infrastructure construction. Under China's "One Belt and One Road (B\&R) Initiative", the high quality Chinese enterprise standards and internationalization are the prerequisite for the realization of international cooperation in science and technology. The novelty of this paper is mainly reflected in the countermeasures and suggestions how to enhance the internationalization level of Chinese enterprise standards in accordance with the initiatives of the "B\&R" construction and the countries concerned actual needs. These include to further improve the technology level and quality of enterprise standards, improve the applicability of Chinese enterprise standards, strengthen international exchanges and cooperation in the field of standardization, establish and improve standard information resource sharing in big data environment, enhance the competitiveness of enterprises, and realize mutual benefit and win-win situation in "B\&R" international cooperation.
\end{abstract}

Keywords. Enterprise Standards, Internationalization, Standardization

\footnotetext{
${ }^{1}$ Corresponding Author, Wei PAN, Standardization Evaluation Department, China National Institute of Standardization, No.4 Zhichun Road, Haidian District, Beijing, China; E-mail: panwei@cnis.ac.cn.

This research was financially supported by Indicators system Optimization and Data Model Research of China National Professional Standardization Technical Committees Examine and Evaluation (Grant NO. 242018Y-5972), Project on Proposal Evaluation and Examination Evaluation Support of the China National Professional Standardization Technical Committees (Grant NO. 242019C-6899), Research on Construction and Application of Enterprise Standardization Capability Evaluation Indicators System (Project No. 2019MK119), and Research on Construction and Application of Enterprise Standardization Capability Evaluation Indicators System (Grant NO. 242019Y-6691-2019).
} 


\section{Introduction}

Standards are the main basis for production of enterprises, and for measuring the quality of products, services and development, and an important guarantee for health, safety and the ecological environment. With the rapid development of the knowledge economy and network economy, the role of technical standards is not only reflected in reducing transaction costs, expanding the scope of market transactions and ensuring product quality, but also a source of high profits for enterprises and a tool to expand the market. In 2014, Chinese President XI Jinping put forward the theory that "standards determine quality, only high standards can lead high quality" [1]. In 2015, Chinese General Office of the State Council issued "China National Standardization System Construction and Development Plan (2016-2020)", which clearly stated that the role of strong enterprise standards should be fully exerted. According to both Chinese and foreign document research, most of the current related research results mainly focus on the standard issues involved in the process of enterprise internationalization. Only a few scholars have carried out research on standards internationalization issues. Most of these studies are based on specific regional standards or sector standards internationalization path research or strategic discussion. For example: "Internationalization of Bank Card Enterprise Standards" [2], "Discussion on the Implementation of Standard Internationalization Strategy for Road and Bridge Construction Enterprises" [3], or "Boosting Competitive Advantages of Small and Medium Manufactures in South Africa by Applying Continuous Improvement and Operational Strategies" which indicates that the importance of standards are recognized both nationally and internationally [4]. This paper conducts research on the internationalization of enterprise standards according to T. R. B. Sanders' standardization theory [5]. The internationalization of enterprise standards is of great significance related to the global development of enterprise products and economy, in particular, to the participating effects of the countries in "One Belt and One Road (B\&R)" infrastructure construction, as well as other cooperation. As Chinese enterprise standards have not been really introduced and implemented abroad for long, its internationalization level does not meet the current needs of B\&R construction. In nowadays a globalized information society, how to give full play to the overall role of standards in "B\&R" construction will greatly promote the international coordinated development and cooperation. This is the main problem and challenge we are facing today.

The research content of this paper intends to make up for the blank of the research on the internationalization of enterprise standards, which takes whole enterprises level as the main body. It has been strived to analyze the main impacts and key issues of enterprise standards in the process of internationalization, to promote the process of internationalization of enterprise standards, and to accelerate the level of internationalization of enterprises.

An integrated methodology of document research, expert interviews and case study was used for conducting this research. Both primary and secondary document resources are collected and analyzed for better investigation. Most of the information and cases in the paper were obtained from the secondary sources, such as: government websites, official news, and journals. In the key issues and suggestions parts of Chinese enterprise standards, some primary resources were collected through face to face interviews or email contacts in some enterprises' experts for gathering their experiences and opinions. Case studies are conducted to reveal the current status and issues in the development of the Chinese enterprise standards internationalization. The qualitative and quantitative research methods are also used in this research. 


\section{The progress of internationalization of Chinese enterprise standards}

Chinese enterprises have been participating in international projects for decades. Generally, the Chinese enterprises going abroad to join cooperative projects might be traced back to 1980's in twenties century. However, the issue of the Chinese enterprise standards internationalization was particularly obvious in recent years. The historic development period can be divided into three stages according to each decade.

\subsection{The first stage: simple labor export on contract 1980-1989}

In the 1980s, the characteristics showed that Chinese enterprises possessed low competitiveness and low influence with low cost. Chinese enterprises' participation in international projects was mainly based on labor export, supplemented by contracted projects. In the face of competition among international companies, it was difficult for Chinese enterprises to stand firm in the market. A huge consumption had been staged even in some project bidding and construction, and they could earn very low profit in those construction for a long time [6].

\subsection{The second stage: labor-intensive construction general contracting projects 1990- 1999}

In the 1990s, the characteristics in this stage showed that Chinese enterprises had certain competitiveness, high efficiency, and low cost. But they were still lack of advanced technology and standards which affected their competitiveness. Chinese enterprises participating in international projects started to transform to labor-intensive general contracting, mainly participating in international competition with cost advantages, but with low economic added value. In those competitions, the internationalization of Chinese standards had also experienced many difficulties. For example: China Road and Bridge Corporate Limited was one of the first four foreign economic enterprises to go abroad. The chief engineer of the company introduced that due to the implementation of European and American standards, their projects undertaken often needed to invite European and American enterprises to participate, or commissioned European and American consulting companies to translate their designs into European and American standard schemes which made problems such as: engineering process increased and engineering cycles lengthened [6].

\subsection{The third stage: engineering procurement construction projects 2000-2019}

After entering the 21st century, the technical advantages of Chinese enterprises had begun to appear. The characteristics in this stage showed technical advantages in some sectors, and more initiative projects and higher efficiency in undertaking the cooperative projects. However, there were lack of high quality technical standards and international recognition which brought a lot of difficulties and issues in the implementing of the projects. Enterprises were actively participating in international market competition. More and more projects had been conducted independently, the projects level was getting better, the projects scale was getting bigger and the technical contents were getting higher. Government framework projects, engineering procurement construction and design, and construction general contract projects had occupied a considerable share [7]. Moreover, Chinese enterprises still lacked of persuasive when trying to adopt Chinese enterprise 
standards for implementation international projects without corresponding standards translation versions as a supporting basis. Chinese companies were still very likely to miss those good opportunities due to language barriers even if some countries had the willingness to adopt Chinese standards. For instance: China Harbor Engineering Corporate Limited had successively contracted a large number of influential economic assistance and contracting projects, such as Pakistan's Gwadar Deep Water Port, Karachi OP-5 Liquid Terminal and Tide Channel Projects. Nevertheless, the construction designs were made by China but European and American standards were adopted since there had been no English translation version of Chinese standards for transportation construction. Another good example was Ethiopia's first highway undertaken by China Communications Construction Company Limited which could use Chinese standards and specifications expressed by the Minister of State of the Ministry of Public Works and Urban Development of Ethiopia, Alkabe Ochube, during his visit to China. Still, Chinese enterprise standards were only developed in Chinese and did not release English and French versions which made Chinese enterprise standards unable to be effectively implemented in project construction [8].

At present, under the situation of accelerate development of economic globalization and market integration as well as B\&R development strategy, the new trend of competition facing the enterprises is from quality competition, service competition, price competition and brand competition to standard competition [3]. Without standard, there will be no quality. Therefore, in order to adapt to the international market, the formulation and implementation of international standard strategy has become an important research topic of enterprise development. The internationalization process of Chinese enterprise standards can be summarized through the three stages of international projects undertaken by Chinese enterprises, which is shown in table 1.

Table 1. Internationalization of Chinese Enterprise Standards in Different Stages

\begin{tabular}{|c|c|c|c|}
\hline Stage & $\begin{array}{c}\text { Chinese Enterprises } \\
\text { Participate } \\
\text { International Trade } \\
\text { Characteristics } \\
\end{array}$ & Strengths and Weaknesses & $\begin{array}{l}\text { Standards } \\
\text { Perspective }\end{array}$ \\
\hline $\begin{array}{l}\text { First } \\
\text { stage } \\
1980 \mathrm{~s}\end{array}$ & $\begin{array}{l}\text { Export simple labor based } \\
\text { on contract projects }\end{array}$ & $\begin{array}{l}\text { Strengths: Low cost } \\
\text { Weaknesses: low competitiveness and low } \\
\text { influence }\end{array}$ & $\begin{array}{l}\text { Not involving } \\
\text { standards }\end{array}$ \\
\hline $\begin{array}{l}\text { Second } \\
\text { stage } \\
1990 \mathrm{~s}\end{array}$ & $\begin{array}{l}\text { Engaged in labor- } \\
\text { intensive construction } \\
\text { general contracting } \\
\text { projects }\end{array}$ & $\begin{array}{l}\text { Strengths: low cost, having certain } \\
\text { competitiveness, high efficiency } \\
\text { Weaknesses: lack of advanced technology } \\
\text { and standards }\end{array}$ & $\begin{array}{l}\text { Recognize the } \\
\text { importance of the } \\
\text { standards }\end{array}$ \\
\hline $\begin{array}{l}\text { Third } \\
\text { stage } \\
2000 \mathrm{~s}\end{array}$ & $\begin{array}{l}\text { Undertake engineering } \\
\text { procurement construction } \\
\text { projects }\end{array}$ & $\begin{array}{l}\text { Strengths: technical advantages in some } \\
\text { sectors, high efficiency } \\
\text { Weaknesses: lack of high quality technical } \\
\text { standards and international recognition }\end{array}$ & $\begin{array}{l}\text { Promote } \\
\text { internationalization } \\
\text { of enterprise } \\
\text { standards }\end{array}$ \\
\hline
\end{tabular}

\section{Status quo of internationalization of Chinese enterprise standards}

Standards internationalization refers to the internationalization activities to meet standards needs in other regions that adopts a series of bilateral or multilateral standardization strategies with the main purpose of promoting national or regional standards [9]. In 2015, the Chinese State Council issued "The Plan for Furthering the Standardization Reforms" [10], which clearly stated that it was necessary to improve the level of internationalization of standards, encourage social organizations, industrial 
technology alliances and enterprises actively participating in international standardization activities, and increase the tracking, evaluation and transformation of international standards. Standards internationalization in advantages and distinctive fields needed to be promoted and Chinese standard brands should be created.

Chinese enterprises, especially state-owned enterprises, should implement the country's major mission of "going global", take the lead in a new mode of international trade in "B\&R" construction and innovation. Their responsibility of leading the internationalization of China's enterprise standards is inexorable [11]. So, Chinese enterprises begun to promote the internationalization process with a positive attitude by attending international conferences and strengthening academic, technical and industrial communication and cooperation in order to thoroughly implement the Chinese national policy following China's economic, social and technological development and progress.

According to statistics from Standardization Administration of China (SAC), by the end of 2018 , there were $1.58 \%$ international standards issued by the International Organization for Standardization and the International Electrotechnical Commission was proposed by China [12]. It could be seen that the overall number of international standards submitted by China was relatively small which did not exactly match the status of China's second largest economy in the world. At the same time, China was still lack of professional and international standardization talents and insufficient experiences in international standardization activities. However, it was undeniable that Chinese enterprises that used to export low-end labor services have increasingly expanded their overseas business in recent years. Chinese enterprise standards and China solutions had increasingly become global.

In 2016, Chinese standards internationalization became a highlight. MombasaNairobi Railway connecting the Kenya's capital Nairobi and Mombasa which was the largest port in the east was built by Chinese enterprises. It was a key project for China and Africa cooperation to promote the construction of the B\&R. Mombasa-Nairobi Railway was the first railway constructed since Kenya's independence and also the first modern new railway in the world that adopted Chinese standards, technologies and equipment. The railway was designed, constructed and operated by China. It established a new model for overseas cooperation in the entire railway industry chain in China and achieved an international new path for integrated construction and management through Chinese standards by Mombasa-Nairobi Railway construction. China Road and Bridge Corporation and the Kenya Railway Company signed an operation and maintenance contract for the Mombasa-Nairobi Railway before it was in use. In line with the contract, operation and maintenance services were provided and technology transfer, personnel training and other cooperation were also made by China Road and Bridge Corporation for the Mombasa-Nairobi Railway to Kenya. This indicated that China's railway construction projects had truly moved from engineering construction to the upper reaches of the industrial chain which drove all-round development of China's railway equipment, capacity and management [13]. Through the overseas cooperation of Chinese enterprises, the internationalization of Chinese enterprise standards had been promoted, and the internationalization of Chinese enterprise standards had in turn driven the overseas development of other related service industries which lead to the spiral upgrade of Chinese enterprises and technology internationalization. 


\section{Key issues in internationalization of Chinese enterprise standards}

The number of registered enterprises in China had exploded since Chinese Prime Minister Li Keqiang proposed to set off a new wave of "mass entrepreneurship and innovation" at Davos Forum in 2014. A number of enterprises had not only reached the world-class scale, but also strived to be at the forefront of the world in terms of technology, management and internationalization. Some of them had built the foundation and conditions to cultivate a world-class enterprise with global competitiveness. At present, China has made some achievements in the process of internationalization of enterprise standards, but problems and challenges still exist. Some enterprises do not know how to participate in international standardization work, or they have encountered one or more difficult problems to be solved in the process of carrying out internationalization of standards etc. Generally, there are three key issues which mainly influence the internationalization of enterprises standards.

Firstly, low level of Chinese enterprises' standardization and language barrier. The gap between Chinese enterprises' standardization level and national quality infrastructure and international advanced level is still quite obvious. Following the increase of the Chinese enterprises' standards in recent years, the contradiction of lacking of English version of Chinese enterprises' standards forms another issue. In the past, except for a small number of export enterprises that required foreign language enterprise standards, mainly Chinese enterprise standards were issued in Chinese. Thus, the pace of standards translation in foreign language was far behind the pace of Chinese companies' internationalization. The globalization of Chinese enterprises, capital, and technology urgently needs the Chinese enterprise standards to go abroad first. However, related language services are relatively lagging behind. Comparing with developed countries, English version of standards in Japan, South Korea, and Germany all account for more than $40 \%$, and China is less than 5\% [14]. Hence, it is great significance to provide foreign language versions of Chinese enterprise standards for other countries to evaluate, adopt, reference, read and use during project implementation.

Secondly, Chinese enterprise standards cannot meet all the requirements of foreign countries. How to solve the inconsistency of standards in international standardization cooperation is the key to promoting the implementation of standards. Different countries have different landform features, different national conditions, different cultures, and different stages of economic development. Affected by various factors, the international application of Chinese enterprise standards has adaptability problems in different countries. Taking the railway field as an example again, enterprises have encountered such issues as: local production conditions led to the failure of the implementation of standards; long rails required by China's railway standards cannot be transported because of without suitable means of transportation; railway operating capacity is not enough in local area with insufficient freight volume and lacking of talents. Such difficulties have directly caused it would not be easy to adopt Chinese enterprise standards in those projects [15]. Thus, the compatibility between standards is particularly important. Enterprise standards internationalization activities are better planed and stepped in line with the regional characteristics, natural conditions, standardization development levels, and engineering characteristics of different countries and regions targeted.

Finally, Chinese enterprises are still lack of participating and contribution to international standardization activities. There is still a big gap between China and developed countries though China has made great progress in participating in international standardization activities. According to 2015 data, China's total GDP 
ranked second in the world, but international standardization participation ranked sixth [16]. "Standards first, technology follow-up" is the usual mode of industrial development in various countries. However, due to historical reasons, there are still many problems and challenges in the internationalization of Chinese enterprise standards. In accordance with incomplete statistics, the overall number of international standards proposed or participated in the formulation and release by China is still too small. On the one hand, it is due to the lack of standard international talents in China. On the other hand, it is due to the lack of experience of participating in international standardization activities by enterprises. Therefore, it is critical for more enterprises, scientific research institutions, and colleges and universities to strive to do better in training and selecting outstanding talents to actively participate in international standardization activities, learning from advanced standardization concepts from developed countries, and accelerating the conversion of technologies in advantageous areas to standards.

\section{Comments on improving internationalization of Chinese enterprise standards}

\subsection{Improve Chinese enterprises standards quality}

Quality and standards are inseparable. Standards are the basis for judging quality, and quality is the result of implementing standards. Whether a project is unqualified or a service can meet the requirements of consumers depends on the corresponding standards. Standards are a reflection of the hard power of core technology. In the process of internationalization, Chinese enterprises need first to improve their technological strength and fully reflect the advanced nature of Chinese enterprise standards. The absolute number of Chinese enterprise standards is quite large. According to a press conference held by the Shandong Provincial Government Information Office, as of the end of 2019, the number of enterprise standards which open to the public in Shandong alone reached more than 163,000, ranking first in the country [16]. However, there is still a lot of work to do for improvement in enterprise standards. It is necessary to promote the coordinated development of standardization, technological innovation, and industrial upgrading by deepening the reform of standardization work, advancing the standardization work system and mechanism innovation.

\subsection{Enhance international applicability of Chinese enterprise standards}

Just as the debate regarding to whether international enterprises should customize or standardize its products. Usually a modified commercial product is substantially similar in each country, but minor adaptations are made on the basic product to conform to local needs and regulations [17]. The modified product policy enables international enterprises to reap the benefits of standardization and centralized production, and local needs [18]. So do the enterprise standards. An in-depth research on the local market needs is especially necessary when Chinese enterprises undertake international projects. It is essential to timely adjust and optimize relevant contents of Chinese enterprise standards combining consideration of specific requirements of project local laws and regulations, market and user needs, economic and social environment, geographical conditions, and climatic characteristics. Through extensive consultations with local authorities of relevant project on the adjusted and optimized standards text, the local applicability of 
Chinese enterprise standards can be improved for meeting the basic requirements, and the best solution of realistic problems can be provided to the project host country.

\subsection{Establish an open concept and strengthen international communication and exchanges in standardization field}

The internationalization of enterprise standards needs to enlarge international exchange and cooperation. Enterprises should first establish the concept of openness, actively participate in international standardization activities, and strive to participate in the formulation and implementation of enterprise standards. International standardization work should not be limited just to accept foreign technologies, but also to promote Chinese enterprises' own technologies and brands. CNPC and Sinopec enterprises are good example on the topic for conducting their brand strategy. Nine measures for the enterprises to conduct the brand strategy are proposed and combination of the standards with the local culture to strain the ability of brand-innovation is one of them [19]. At the same time, enterprises can also actively carry out international standardization pragmatic cooperation for enhancing their ability and level of substantial participation in international standardization activities. International standards related with the enterprise industry or the project can be paid attention for information tracking and evaluation for accelerating the Chinese enterprise standards transformation into international standards. Enterprises can also carry out Chinese and foreign standards differential collaborative research by exchanging personnel, project research and academic exchanges etc. with standardization organizations or institutions in the project host country. It will help to understand the technology and standardization gap and offer an opportunity to learn from each other to absorb the advanced technology and experience from both sides, and then, to improve the overall level of internationalization of enterprise standards.

\subsection{Adopt big data technology to enhance the enterprise competitiveness and standardization level}

Big data can realize the high efficiency and conciseness of enterprise process, and help enterprises deal with more and huger "data flow". At the same time, working in the distributed big data environment can greatly improve the enterprise competitiveness and its standardization level. The visualized description tool of big data can help decision makers and analysts to mine the relationship between different data, and can also use visualized tools to design special model to query the required data, such as querying the implementation progress of enterprise standardization construction plan at a certain time and place. Future development of big data, cloud computing and Internet of things will bring unprecedented opportunities for the standardization and internationalization of Chinese enterprises.

On the basis of the enterprise standards information public service platform hosted by SAC, it is possible to expand the information resources of enterprise standards at home, strengthen the network coordination and cooperation in the preparation and revision of enterprise standards, and carry out opening and sharing of network enterprise standards resources. Using advanced information technology, the Chinese enterprises may acquire the standard information of same sector enterprises accurately, timely and systematically, avoid decentralization and duplicate investment of standard information resources, and support the international development of enterprises to the maximum extent. Chinese enterprises should actively integrate enterprise standard construction 
with international standard to unify the standard makers, users and managers to improve the efficiency and quality of the implementation of internationalization strategy of enterprise standards.

Supported by the big data technology and international standards organizations, Chinese enterprises may realize the localization, internationalization and globalization of enterprise standards driven by advantageous of our products and projects in order to support the internationalization of Chinese enterprise standards.

\subsection{Produce more values for international community}

Chinese enterprises shall take the initiative to assume more social responsibilities in the process of internationalization of its standards. More profound values for local development shall be created with attention while enterprises themselves are developing and strengthening. Enterprises social responsibility can be reflected by cooperating with local communities, making beneficial investments in the local area, developing relationships with local employees and families, and participating in activities such as environmental protection, technology transfer, and community development. The Chinese enterprises may help local communities to maximize their benefits while striving to enhance its own strength and influence during process of internationalization of standards. At the same time, we should strengthen the translation and publicity of Chinese enterprise standards in foreign languages, help project host countries of B\&R construction to understand and implement the Chinese enterprise standards, and better accomplish the tasks of high quality and standardized infrastructure construction.

\section{Conclusion}

This paper summarizes the experiences and issues of Chinese enterprises in the process of undertaking international projects and demonstrates the important role of standards in the development of international projects. Several cases show that global oriented Chinese enterprise standards are the general trend of global integrated economic development and the necessary requirements for Chinese enterprises to cooperate with other countries in depth. It is also the most effective way to achieve the export of technology, products, management and services which is an inevitable choice to expand international market share and provide good quality services to the end users.

Through this research, it may be concluded that Chinese enterprise standards internationalization is a critical step in conducting B\&R initiative, and the important mission of implementing China's "going global" strategy. Chinese enterprise should be a pioneer and leader in building a new international trade order and new mode of B\&R. Its responsibility of leading the internationalization of Chinese enterprise standards is inexorable. Chinese enterprises have realized a great change from quantity accumulation to quality, from the initial simple labor output to the later engineering output, and then to the current standard and program output. Only when Chinese enterprise standards are closely integrated with international standards, carry out extensive international cooperation, establish a data sharing mechanism based on big data, and provide translation of both Chinese and foreign languages standards, can the compatibility, applicability and utilization of Chinese enterprise standards be continuously improved. Modern enterprises should export mature, reliable and advanced industrial standards, and give priority to the implementation and operation of all production and construction 
activities in accordance with the norms and standards. Only in this way can we bring the most satisfactory return to the stakeholders and improve the competitiveness of the enterprise.

To solve the problems faced by the internationalization of Chinese enterprise standards, the paper puts forward some suggestions for the future development that includes improving Chinese enterprises standards quality, enhance international applicability of Chinese enterprise standards, establish an open concept and strengthen international communication and exchanges in standardization field, adopt big data technology to enhance the enterprise competitiveness and standardization level, and produce more values for international community and better contribute to the international standardized infrastructure construction. Chinese enterprises may further support the economic development strategies of relevant countries, improve ability to participate substantially in international standardization activities, and continuously increase the quantity and quality of Chinese enterprise standards in its advantageous technology and fields for better implementing of the enterprise standards internationalization in the future. By deepening bilateral and multilateral pragmatic exchanges and cooperation with other countries or regions in standardization, sharing of information resources and scientific and technological achievements, the purpose of coordinated development and win-win cooperation can be finally achieved.

Some other considerations for the research in the future can be concluded as: Following this research results, it is hoped that those of the national standardization organizations and foreign-related enterprises may be aware of the significance and far reaching influence of establishing overall standardization strategy deployment at enterprise strategy level. The foreign-related enterprises and the standardization community will pay attention to the issue of internationalization of enterprise standards. More experts and scholars can be attracted to carry out in-depth research in related fields by combing and summarizing the key issues and precautions for the internationalization of corporate standards. Particularly, further research on the applicability of standards, comparative analysis and complement of the enterprises standards between Chinese enterprises and the projects host countries shall be the future study topics in the near future. Establishment of regional standardization cooperation mechanisms and specific contents as well as standardized tools for countries along the "B\&R Initiatives" can be explored which can benefit global and regional foreign-related enterprises to promote international projects.

\section{References}

[1] People's Daily. Commentator of People's Daily: Sticking to a High Starting Point, High Standards, and High Quality: Discourse on Solidly Promoting the Second Batch of Mass Line Education Practice Activities. People's Daily; 2014; DOI=http://opinion.people.com.cn/n/2014/0212/c1003-24329851.html.

[2] Internationalization of Bank Card Enterprise Standards. Electronic Finance; 2014; 06:99-101.

[3] Wen G, Lu Y, and Wu H. Discussion on the implementation of standard internationalization strategy for road and bridge construction enterprises. Transportation Enterprise Management; 2015; 30 (09):1-3.

[4] Kholopane P. Boosting Competitive Advantages of Small and Medium Manufactures in South Africa by Applying Continuous Improvement and Operational Strategies. PICMET 2016 - Portland International Conference on Management of Engineering and Technology: Technology Management For Social Innovation, Proceedings; 2017 January 4; p. 1442-1447.

[5] Sanders TRB. The Aims and Principles of Standardization. ISO; 1973; DOI=https://www.iso.org/sites/edumaterials/trbsaunders.pdf. 
[6] Wang NN. Going Out of Standards and Discourse Right. Transportation Construction \& Management; 2011; 11:50-51.

[7] Ding Y. On the Internationalization of Compilation and Publication of Foreign Standards of Chinese Enterprise Standards. Publishing Reference; 2017; 11:32-34.

[8] Enterprise Culture. Financial Times: Chinese Enterprise Standards Internationalization Opens a Breakthrough. $\quad$ Enterprise Culture; 2019; DOI=http://www.ccccLimited.cn/news/mtjj/201309/t20130901_18253.html.

[9] Chen Y. Research on the Relationship Between Standard Internationalization and International Standardization. Railway Technology Supervision; 2016; 44:1-3.

[10] Chinese State Council. Notice of the State Council on Printing and Distributing Reform Plans for Deepening Standardization Work. Chinese State Council; 2015; 13.

[11] Liu FY. Rethinking China's standard "going global". Journal of Consumption Guide; 2018; 25:127-128.

[12] Mao F and Sheng LX. The Status Quo and Path Improvement of Chinese Standards Internationalization Under the Background of the New Trend of International Standardization Development. Standards Science; 2018; 12:88-91.

[13] Hu ZY. Seeing the Enlightenment of "China's Enterprise Standards" Boosting the "One Belt and One Road" from the Mombasa-Nairobi Railway. World Knowledge; 2017; 14:58-59.

[14] Mao F. Thoughts on the Standardization Development of Countries along the "One Belt and One Road" and the Internationalization of Chinese Enterprise Standards. Proceedings of the International Forum of Standardization and Governance; 2017; 5.

[15] Song MS. et al. Research on Railway Standard System under "One Belt and One Road" Facilities Connectivity. China Enterprise Standardization; 2018; 11:56-61.

[16] China International Chamber of Commerce. Difficulties and Solutions for Chinese Enterprises Internationalization. China International Chamber of Commerce; 2017 , DOI=http://vnfjba.com/cn/index.php? $\mathrm{m}=$ content $\& \mathrm{c}=$ index\&a=show\&catid=18\&id=370.

[17] Takeuchi H. and Porter ME. Three roles on international marketing in global strategy. In: Porter ME. (Ed.). Competition in Global Industries; Harvard Business School Press; Boston, 1986. p. 111-146.

[18] Hadjinicolaa GC. and Kumarb KR. Modeling Manufacturing and Marketing Options in International Operations. Int. J. Production Economics; 2002; 75:287-30.

[19] Zhang B. and Chen C. How CNPC and Sinopec enterprises create internationalized brands. Natural Gas Industry; 2004; v 24, n 11, p 156-159+20. 